\title{
Identification of protein targets
} therapies

\author{
Margaret Simonian ${ }^{1,2^{*}}$, Rachel R. Ogorzalek Loo ${ }^{2}$, Nalaka Rannulu², Joseph A. Loo², Mark P. Molloy ${ }^{3}$ \\ and Marcus A. Stoodley ${ }^{1}$
}

\begin{abstract}
Background: To develop a new molecular targeted treatment for brain (AVMs), identification of membrane proteins that are localised on the AVM endothelium is crucial. Current treatment methods are surgery and radiosurgery. However, complete occlusion post radiosurgery are achieved within 3 years, while patient remain at risk of haemorrhage. This study aims to identify potential protein targets in AVM endothelial cells that discriminate these vessels from normal vessels; these proteins targets will be investigated for the molecular therapy of brain AVMs to promote rapid thrombosis after radiosurgery.

Methods: We employed in vitro biotinylation that we developed, and mass spectrometry to detect cell surfaceexposed proteins in cultures of murine cerebral endothelial cells (bEnd.3). Two forms of mass spectrometry were applied (iTRAQ-MS and MS ${ }^{\mathrm{E}}$ ) to identify and quantify membrane protein expression at various time-points following irradiation which simulates a radiosurgical treatment approach. Immunocytochemistry was used to confirm the expression of selected membrane proteins. ProteinPilot V4.0 software was used to analyse the iTRAQ-MS data and the $M^{E}$ data was analysed using ProteinLynx Global Server version 2.5 software.

Results: The proteomics data revealed several differentially expressed membrane proteins between irradiated and non-irradiated cells at specific time points, e.g. PECAM-1, cadherin-5, PDI, EPCR and integrins. Immunocytochemistry data confirmed the expression of these proteins.

Conclusion: Cell surface protein biotinylation and proteomics analysis successfully identified membrane proteins from murine brain endothelial cells in response to irradiation. This work suggests potential target protein molecules for evaluation in animal models of brain-AVM.
\end{abstract}

Keywords: Endothelial cells, Biotinylation, Membrane proteins, Irradiation, Arteriovenous malformations

\section{Background}

Brain arteriovenous malformations (AVMs) consist of a tangle of abnormal arteries and veins linked by one or more fistulae [8]. The cause of brain AVMs is not well

\footnotetext{
*Correspondence: margaret@chem.ucla.edu

2 David Geffen School of Medicine, Department of Biological Chemistry, University of California Los Angeles (UCLA), 611 Charles E. Young Drive East, Los Angeles, CA 90095, USA

Full list of author information is available at the end of the article
}

known, with some theories suggesting that they may be caused by a clot or a rupture of blood vessels during fetal development [23], while others suggest that they develop postnatally, undergoing a period of growth in childhood or early adulthood and that the growth may be caused by endothelial shear stress that stimulates growth factor expression [18].

Patients with AVMs present with headaches, seizures, or, most commonly hemorrhage. Current treatment options for brain AVMs are surgery, embolization and 
stereotactic radiosurgery. The goal of AVM treatment is to prevent haemorrhage and the choice of treatment depends on many factors, including AVM location (eloquent or non-eloquent brain) and size [8, 38, 39].

Stereotactic radiosurgery is a procedure that delivers a single, localized, high dose of radiation to the target through the intact skull using a linear accelerator (LINAC) or Gamma Knife [21, 27]. This treatment is suitable for lesions $<3 \mathrm{~cm}$ in diameter and located in eloquent areas where surgery can cause neurological deficits [8]. However, vascular occlusion after radiosurgery can take up to 3 years to complete, and patients remain at risk of haemorrhage during this time $[9,22]$. Approximately one-third of AVMs are unsuitable for current treatment methods, therefore there is a need for new treatments, especially for large and deep lesions [7, 14].

We have been investigating endothelial expressed molecules as targets for AVM molecular therapy. Specifically in this study, it is proposed that radiosurgery can modify the expression of endothelial cell surface discriminating proteins and hence provide a molecular targeting site for delivering secondary agents (e.g. pro-thrombotic molecules). To achieve this goal, we have developed in vitro biotinylation methodology to label endothelial cell surface proteins $[35,36]$, and we employed that methodology here to identify protein targets using two advanced quantitative mass spectrometry techniques, iTRAQ-MS and $\mathrm{MS}^{\mathrm{E}}$.

$\mathrm{MS}^{\mathrm{E}}$ is a label free quantitative MS technique, while iTRAQ-MS is a labelled-based proteomics method. $\mathrm{MS}^{\mathrm{E}}$ enables the identification as well as quantification of proteins, improves sequence and proteome coverage, and has lower false positive rates. These advantages are most dramatic for the low abundant proteins such as endothelial membrane proteins. Therefore we used these two proteomics methods to validate our proteomics data and to increase the number of membrane proteins identification.

Mouse brain endothelial cell cultures (bEnd.3) were studied at 6, 24, 48 and $72 \mathrm{~h}$ post irradiation, while non-irradiated cells were served as controls. Eightplex iTRAQ-MS and $\mathrm{MS}^{\mathrm{E}}$ analyses were carried out to compare the differences in protein expression between irradiated and control samples at each time point. Immunocytochemistry was subsequently used to confirm the expression of these proteins.

\section{Methods}

\section{Mouse endothelial cell cultures (bEnd.3)}

Cryopreserved bEnd.3 cells obtained from (American Type Culture Collection, VA, USA) were cultured in DMEM with $4.5 \mathrm{~g} / \mathrm{L}$ D-glucose, $4 \mathrm{mM}$ L-glutamine, and $0.11 \mathrm{~g} / \mathrm{L}$ sodium pyruvate (Gibco, CA, USA). $10 \%$ fetal bovine serum albumin (Invitrogen, Gibco), HEPES (Sigma, Aldrich, MO, USA) and antibiotics (Invitrogen, Gibco) were added to the DMEM and incubated in a 5\% $\mathrm{CO}_{2}$ atmosphere at $37{ }^{\circ} \mathrm{C}$. Cells were seeded in $75 \mathrm{~cm}^{2}$ tissue culture flasks, $15-17 \mathrm{~mL}$ of the growth media were added until about $80 \%$ confluent with medium renewal every $2-3$ days.

\section{Cell density and total protein concentration}

bEnd. 3 cells were counted using Bio-Rad Automated Cell Counter TC10 (Bio-Rad, Castle Hill, NSW, Australia). Cells viability was assessed with Trypan Blue Solution (0.4\%) (Sigma Aldrich, MO, USA). Equal amounts of cells were seeded in each flask. The total protein concentration of cell cultures was determined using Micro BCA kit (Pierce, IL, USA). A standard curve was generated by using bovine serum albumin. The density of bEnd. 3 cells was approximately $1 \times 10^{5}$ cells $/ \mathrm{mL}$ and total protein concentration was $1.6 \mathrm{mg} / \mathrm{mL}$.

\section{Irradiation of bEnd. 3 cells}

bEnd. 3 cells were irradiated once they reached $80 \%$ confluence in their culture flasks and samples collected at 6 , 24,48 and $72 \mathrm{~h}$ post irradiation. Non irradiated cells were also collected at the corresponding time points. The irradiation dose used in this study was $25 \mathrm{~Gy}$, which is the same dose currently are being used for stereotactic radiosurgery treatment for brain AVMs. The cells used for the iTRAQ study were irradiated at Macquarie University Hospital using 6 MV photons on an Elekta Synergy linear accelerator, and the cells used for the $\mathrm{MS}^{\mathrm{E}}$ study were irradiated at UCLA Radiation Oncology department using RS320 research system (Varian Medical Systems) that uses a metal ceramic $300 \mathrm{kV}$ X-ray tube with an integral high voltage receptacle and cooling system. The system is enclosed in a ray proof housing that contains fittings for water hose connections. The X-ray tube output limits are; Voltage $30-310 \mathrm{kV}$, Current $1.0-30 \mathrm{~mA}$, Power $3000 \mathrm{~W}$. Cells were returned to the incubator immediately after irradiation. None-irradiated cells were used as controls at each time point.

\section{In vitro biotinylation of bEnd. 3 cells}

Surface biotinylation was performed on irradiated and control bEnd.3 cultures using our developed protocol [35]. Briefly, each $75 \mathrm{~cm}^{2}$ flask containing approximately $1 \times 10^{6}$ cells was washed four times with PBS pH 7.4. Twenty millilitres of PBS containing $67 \mu \mathrm{M}$ Sulfo-NHSLC-Biotin (Pierce, IL, USA) were added to the flasks and incubated for $5 \mathrm{~min}$ at room temperate. The biotinylation reaction was terminated by adding Tris- $\mathrm{Hcl} \mathrm{pH} 7.5$ to reach a final concentration of $670 \mu \mathrm{M}$. After $5 \mathrm{~min}$ incubation the cells were washed four times with PBS 
and harvested with $2-3 \mathrm{~mL}$ of lysis buffer containing $2 \%$ $\mathrm{w} / \mathrm{v}$ NP40, $0.2 \% \mathrm{w} / \mathrm{v}$ SDS and protease inhibitor (Complete, EDTA-free, Roche, Switzerland) and kept on ice for $30 \mathrm{~min}$.

\section{Capture of biotinylated proteins}

Streptavidin Sepharose high performance (GE health care, Australia) was used to capture biotinylated proteins, according to the protocol of Simonian et al. [35]. Five hundred microlitres of streptavidin Sepharose were washed first three times with buffer A containing (1\% w/v NP40, $0.5 \% \mathrm{w} / \mathrm{v}$ SDS in PBS). Samples were then incubated with washed streptavidin Sepharose for $2 \mathrm{~h}$ in room temperature. Streptavidin Sepharose was pelleted by centrifugation at $1600 \mathrm{~g}$ for $5 \mathrm{~min}$. Unbound proteins were removed by washing three times with buffer $\mathrm{A}$, once with buffer $\mathrm{B}$ $(0.1 \% \mathrm{w} / \mathrm{v} \mathrm{NP} 40,0.5 \mathrm{M} \mathrm{NaCl}$ in PBS) and once with digestion buffer (0.25 mM TEAB) for iTRAQ-MS analysis. For $\mathrm{MS}^{\mathrm{E}}$ analysis unbound proteins were removed by washing three times with $1 \% \mathrm{v} / \mathrm{v}$ TX-100, once with $0.1 \% \mathrm{w} / \mathrm{v}$ SDS and five times with digestion buffer $(50 \mathrm{mM}$ ammonium bicarbonate). The use of high salt concentration and NP40 detergent in the washing buffers, will minimise the nonspecific interactions of biotin and streptavidin.

\section{Tryptic digestion of biotinylated proteins and iTRAQ labelling}

Streptavidin Sepharose was re-suspended in $200 \mu \mathrm{L}$ of digestion buffer. Twenty microlitres of trypsin were added and incubated overnight at $37{ }^{\circ} \mathrm{C}$. The samples were centrifuged at $14,100 \mathrm{~g}$ for $2 \mathrm{~min}$ at room temperature. Supernatant was removed and dried in the SpeediVac until complete dryness. Samples were resuspended in 0.5 M TEAB and labelled with iTRAQ 8-plex reagents kit (Applied Biosystems, Foster City, CA) as follows [Sample $(6)=113$, control $(6)=114$, sample $(24)=115$, control $(24)=116$, sample $(48)=117$, control $(48)=118$, sample $(72)=119$, control $(72)=121]$.

\section{Strong cation exchange chromatography and Nano-LC ESI MS/MS}

iTRAQ labelled samples were pooled in a 1:1 ratio and fractionated by strong cation exchange chromatography (SCX) using Macro-Prep High S Ion Exchange Support (Bio-rad, Cat\# 158-0030) per the manufacturer's instructions and the cleaned sample was collected and dried. The cleaned SCX fraction was resuspended in $90 \mu \mathrm{L}$ of desalting solution containing $0.1 \%$ trifluoroacetic acid and $2 \%$ acetonitrile $97.9 \%$ water. Thirty-nine microliters of the resuspended solution was loaded on a reverse phase peptide Captrap (Michrom Bioresources) then desalted with the desalting solution at a rate of $10 \mu \mathrm{L}$ per min for $13 \mathrm{~min}$. The trap was switched on line with a
$150 \mu \mathrm{m} \times 10 \mathrm{~cm} \mathrm{C18} 3 \mu \mathrm{m}$ 300A ProteCol column (SGE). The buffer solution A contained $99.9 \%$ water, $0.1 \%$ formic acid and buffer solution B was increased from 5 to 90\% in $120 \mathrm{~min}$ in three linear gradient steps to elute the peptides. The column was then cleaned with $100 \%$ buffer $\mathrm{B}$ for $15 \mathrm{~min}$ and equilibrated with buffer A for $30 \mathrm{~min}$. The reverse phase nano LC eluent was subject to positive ion nanoflow electrospray analysis. In IDA (information dependent acquisition) mode a TOFMS scan was acquired $(m / z 380-1600$ for $0.5 \mathrm{~s})$, with the three most intense multiply charged ions (with counts $>70$ ), then subjected to MS/MS analysis. MS/MS spectra were gathered for $2 \mathrm{~s}$ in the mass range of $\mathrm{m} / z$ 100-1600 with a modified (Enhanced All Q2) transition setting to favour low mass ions so that the reporting iTRAQ tag ion (113, $114,115,116,117,118,119$ and 121) intensities were enhanced for quantitation (Australian Proteome Analysis Facility, APAF protocol).

\section{Chromatographic separation and $\mathrm{MS}^{\mathrm{E}}$ analysis}

To support the iTRAQ-MS analysis we carried out an independent MS experiment using a label-free method known as $\mathrm{MS}^{\mathrm{E}}$. Cultured cells were treated by irradiation and samples collected after 6, 24 and $48 \mathrm{~h}$. Control samples were also collected at these timepoints.

Chromatographic separation of the tryptic peptides was achieved using an ultra-performance liquid chromatography (UPLC) system (Waters nanoAcquity UltraPerformance UPLC) coupled to a Waters Xevo quadrupole time-of-flight mass spectrometer. Peptides were separated with a UPLC BEH C18 Column $(1.7 \mu \mathrm{m}$, $75 \mu \mathrm{m} \times 150 \mathrm{~mm}, 10 \mathrm{~K} \mathrm{psi})$. The mobile phase, used at a flow rate of $0.3 \mu \mathrm{L} / \mathrm{min}$, with a gradient of a mixture of (A) $0.1 \%$ formic acid in water and (B) $0.1 \%$ formic acid in acetonitrile was programmed as follows: initial $97 \% \mathrm{~A}$ for $1 \mathrm{~min}$, decreased to $60 \% \mathrm{~A}$ in $60 \mathrm{~min}$, then decreased to $5 \%$ for $2 \mathrm{~min}$, held at this for $15 \mathrm{~min}$, again increased to $97 \% \mathrm{~A}$ in $3 \mathrm{~min}$. The column temperature was set at $28{ }^{\circ} \mathrm{C}$.

Mass spectrometry analysis was performed utilizing a Waters Xevo quadrupole time of flight (Q-TOF) micro ${ }^{\text {TM }}$ mass spectrometer coupled directly to Waters nanoACQUITY UPLC system (Waters Corp). All analysis was performed using positive mode electrospray ionization (ESI). The LC-mass spectrometer was operated in the $\mathrm{MS}^{\mathrm{E}}$ data independent acquisition mode. LC MS data was collected in an alternating low energy MS and elevated energy $\mathrm{MS} / \mathrm{MS}\left(\mathrm{MS}^{\mathrm{E}}\right)$ mode of acquisition. In low energy MS mode the data were collected at a constant collision energy of $6 \mathrm{eV}$. In elevated energy MS/MS mode the collision energy was ramped from 15 to $40 \mathrm{eV}$ on laboratory frame energy to collect product ions of all precursors identified from the MS scan. 


\section{Immunocytochemistry}

The following protocol was optimised on bEnd.3 cells then used. Cells were grown on cover slips in six well cell culture plates (CELLSTAR, Indiana, USA), and fixed with $4 \%$ paraformaldehyde for 6 min cell were washed with PBS three times and permeabilized with $0.2 \%(\mathrm{v} / \mathrm{v})$ Tween-20 in PBS for another $6 \mathrm{~min}$. After washing with PBS X3 and 1\% (w/v) bovine serum albumin three times, cells were stained for anti-cadheren 5 (CD144), anti-CD109 (BD Pharmingen) and anti-protein disulfide isomerise (PDI) (Sigma) antibodies. The corresponding secondary antibodies were labelled with Alexa Fluor 488 (Invitrogen) and nuclei were stained with DAPI (Invitrogen). Slides were then mounted with Fluoromount mounting medium (DAKO) and examined with fluorescent microscope (Leica, Microsystems, Germany). Cells were stained at $6,24,48$ and $72 \mathrm{~h}$ post irradiation. Control cells were also stained at each time point.

\section{Data analysis ITRAQ-MS}

The nano-LC ESI MS/MS data were submitted to ProteinPilot V4.0 software (AB Sciex) for data processing using SwissProt database and Mus musculus species. Bias correction was selected. The detected protein threshold (unused ProtScore) was set as $>1.3$, better than $95 \%$ confidence with $p$ values $<0.05$. The search parameter settings were: enzyme, trypsin; maximum missed cleavages, 1; fixed modification: carbamidomethyl (Cys), iTRAQ (N terminus), iTRAQ (Lys), variable modifications, phosphorylation (Ser, Thr, Tyr) and oxidation (Met); peptide tolerance, $65 \mathrm{ppm}$; MS/MS tolerance, $0.15 \mathrm{Da}$. The number of proteins in the database was 16,307. The hypothesis being tested for ProteinPilot software was "The actual protein ratio is 1 and the observed protein ratio is different than 1 by chance." This null hypothesis is not true when the difference in expression is real. That is, the difference between the observed ratio and 1 is due to something real, not random variation. The smaller the $p$ value, the more likely that expression difference is real.

\section{$M S^{\mathrm{E}}$}

The LC MS and LC MS/MS data were processed using ProteinLynx Global Server (PLGS) version 2.5 (Waters Corporation). The quantification of protein levels was achieved by the addition of an internal protein standard (BSA trypsin digest) to which the data set was normalized. The protein identification was based on MS/MS peak lists which were generated by $\mathrm{MS}^{\mathrm{E}}$ data independent collision induced fragmentation using a Mus musculus database. Protein identifications were accepted with greater than three fragment ions per peptide, seven fragment ions per protein and one unique peptide per protein identified. Carbamidomethyl cysteine was set as a fixed modification while oxidized methionine was set as a variable modification. Trypsin was set as a proteolytic enzyme, and up to two missed cleavages were allowed. Peptide tolerance set at $10 \mathrm{ppm}$ with fragment ion tolerance of $0.5 \mathrm{amu}$.

When a peptide was not detected in the MSE experiment a nominal amount of 0.01 was reported to avoid zeros in subsequent calculations.

\section{Results \\ Proteomics \\ iTRAQ-MS analysis}

The proteomics quantitative analysis of 8-plex iTRAQMS was carried out with three independent biological replicates. From the first iTRAQ-MS experiment, 102 proteins were identified from a total of 3828 spectra. The second iTRAQ-MS identified 132 proteins from a total of 3938 spectra, and the third iTRAQ-MS, identified 83 proteins from a total of 5282 spectra. A total of 50 membrane proteins were identified from all three iTRAQMS experiments. Additional file 1: Table S1 contains the names of these proteins, and Additional file 2: Table $S 2$ is the raw data for one of iTRAQ-MS run.

Our proteomics analysis focused on the proteins that were present and showed differences in expression level between irradiated and control samples in at least two out of the three independent iTRAQ-MS runs for statistical significance analysis. Eleven proteins were significantly differentially expressed in at least two out of the three iTRAQ-MS runs at different time points. At $6 \mathrm{~h}$ after irradiation, filamin $\mathrm{B}$, protein disulfide isomerase, and vimentin were up-regulated in irradiated cells. At $24 \mathrm{~h}$, myosin was up-regulated in irradiated cells, while at $48 \mathrm{~h}$, lamin, plectin, vimentin, actin cytoplasmic 2 and histone $\mathrm{H} 2 \mathrm{~A}$ were up-regulated in irradiated cells and at $48 \mathrm{~h}$, plectin, vimentin, myosin and histone $\mathrm{H} 4$ were upregulated in irradiated cells at $72 \mathrm{~h}$.

The membrane proteins that were up-regulated in irradiated samples, compared to the controls at different time points, are of interest in this study since those on the surface of endothelial cells potentially can be targeted by ligands to induce thrombosis in AVM vessels post radiosurgery. We found six up-regulated membrane proteins at different time points, however, some membrane protein up-regulation, although significant at their MS run $(p<0.05)$, was only observed in one out of the three iTRAQ-MS runs.

\section{$M S^{\mathrm{E}}$ analysis}

The $\mathrm{MS}^{\mathrm{E}}$ experiment was repeated so that mass spectrometry data were independently obtained twice. A total of 36 mass spectrometry runs were analysed from 
6 irradiated and 6 control samples, each run in triplicate. The total number of proteins identified in bEnd.3, by two independent $\mathrm{MS}^{\mathrm{E}}$ analyses in irradiated (R) and control (C) samples at each time point were as follows; at $6 \mathrm{~h}, 163$ proteins in $(\mathrm{R})$ and 229 in $(\mathrm{C})$ : at $24 \mathrm{~h}, 407$ proteins in $(\mathrm{R})$ and 371 in $(C)$ : at 48 h, 216 proteins in $(R)$ and 276 in $(C)$. While the number of membrane proteins were 10 in $(\mathrm{R})$ and 27 in $(C)$ at $6 \mathrm{~h} ; 47$ proteins in $(\mathrm{R})$ and 31 in $(\mathrm{C})$ at $24 \mathrm{~h} ; 18$ proteins in $(\mathrm{R})$ and 13 in $(\mathrm{C})$ at $48 \mathrm{~h}$ post-irradiation, making a total of 146 membrane proteins.

Our proteomics analyses focused on the membrane proteins that were present in both independent $\mathrm{MS}^{\mathrm{E}}$ data at three time points. Table 3 indicates the membrane proteins shared between irradiated $(\mathrm{R})$ and control $(\mathrm{C})$ samples at each time point with their average concentrations on column, average protein masses and number of times identified in the runs. The Additional file 3: Table S3 includes all the proteins identified in both $\mathrm{MS}^{\mathrm{E}_{\mathrm{S}}}$ while Additional file 4: Table S4 shows the raw data for one of the fractions of control sample at $6 \mathrm{~h}$ time point.

Further analysis was focused on the membrane proteins that were present in at least three out of the six $\mathrm{MS}^{\mathrm{E}}$ runs in $\mathrm{R}$ and $\mathrm{C}$ groups at each time point. This criterion was observed only at 24 and $48 \mathrm{~h}$ time points, and is presented in (Tables 4, 5).

Cadherin 5 (CD144) was expressed on the cell membrane of irradiated and non-irradiated cell cultures. The expression intensity in the irradiated cells at 24 and $48 \mathrm{~h}$ was greater than controls (Fig. 1). This observation was in agreement with iTRAQ-MS data at $24 \mathrm{~h}$ but not at $48 \mathrm{~h}$ (Table 2), and was in agreement with $\mathrm{MS}^{\mathrm{E}}$ data at 24 and $48 \mathrm{~h}$ (Table 3). A change in cell shape was also noted at 48 and $72 \mathrm{~h}$. The Additional file 5: Table S5, combine Tables $1,2,3,4,5 \&$ the staining data in one table.

\section{Platelet endothelial cell adhesion molecule-1}

PECAM-1 expression intensity on the cell membrane was higher in irradiated cells at 24,48 and $72 \mathrm{~h}$ postirradiation compared to the control cells, however the intensity levels decreased gradually at 48 and $72 \mathrm{~h}$ in irradiated cells (Fig. 2). The proteomics data at 24 and $72 \mathrm{~h}$ are in agreement with the staining data that show elevated PECAM-1 after irradiation (Table 3). Morphological changes also noted after $24 \mathrm{~h}$ of irradiation, this may due to the long term effect of irradiation on cells viability.

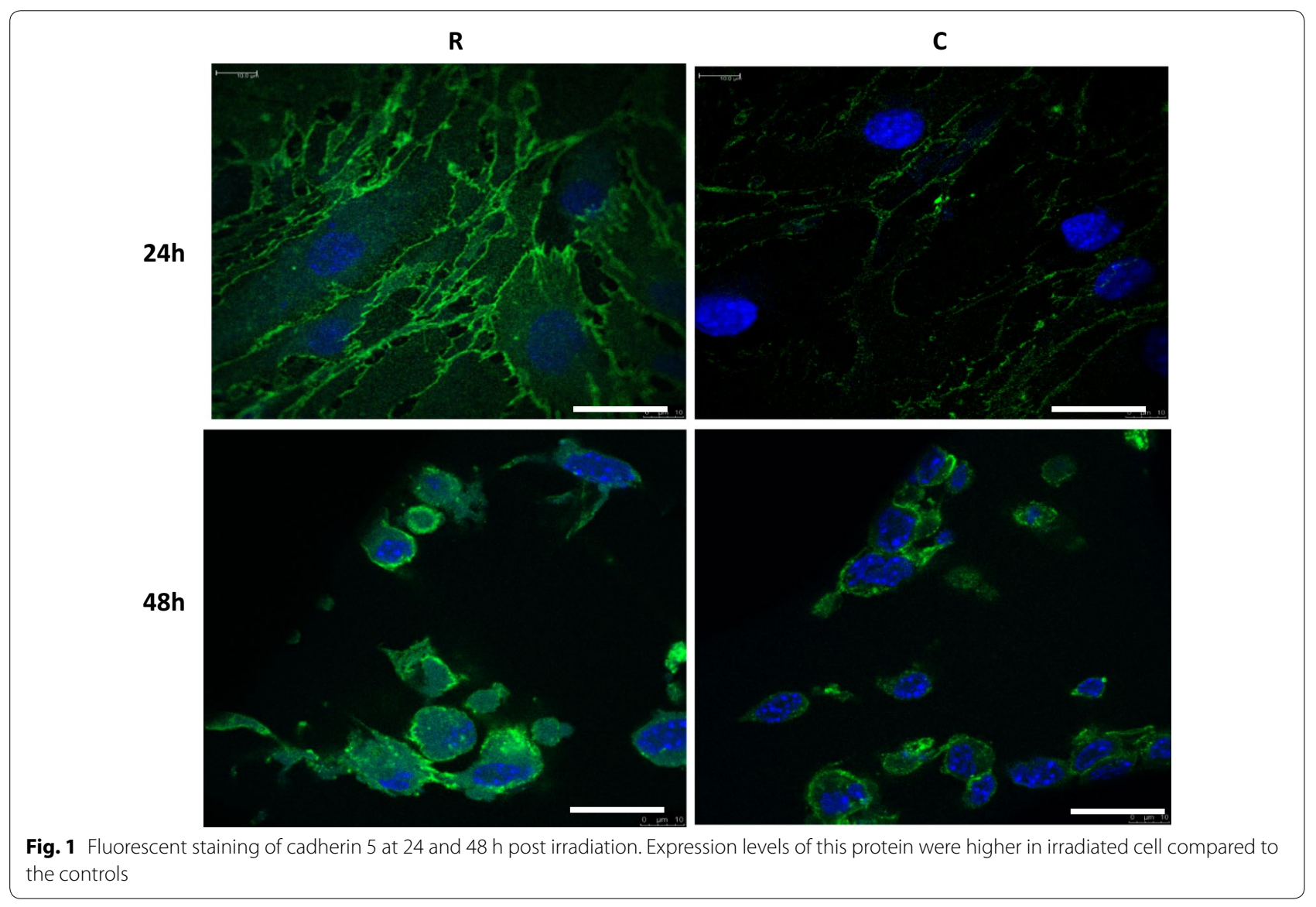




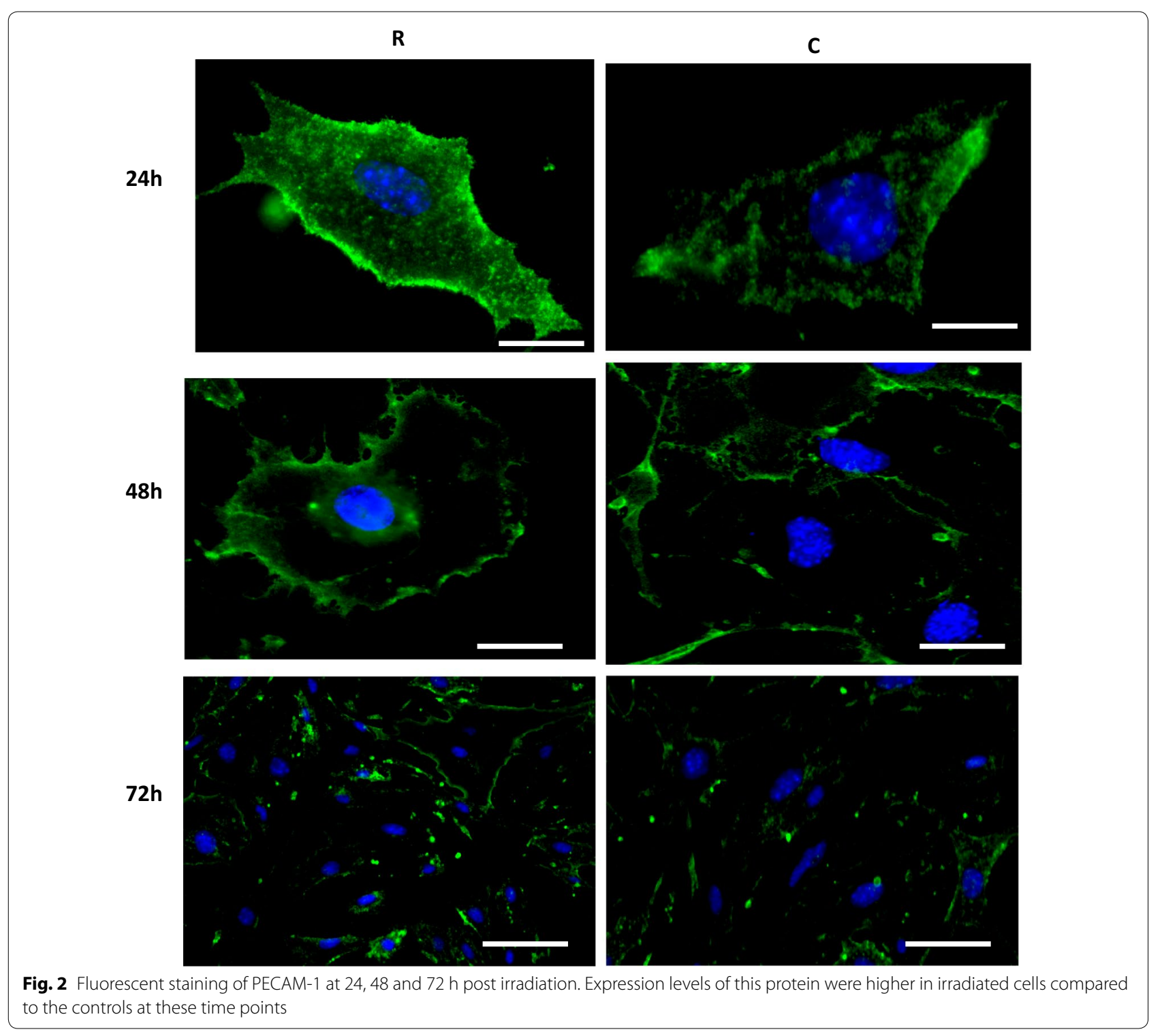

\section{CD109}

The CD109 was mainly expressed in the cytoplasm of irradiated and control cells. The expression intensity in the irradiated cells was higher at $6 \mathrm{~h}$ compared to the control, but lower at $48 \mathrm{~h}$ compared to the control (Fig. 3). This was consistent with iTRAQ-MS (Table 3).

\section{Protein disulfide isomerise (PDI)}

PDI was expressed in the cytoplasm of irradiated and control cells. The expression intensity in the irradiated cells was greater in the irradiated cells than in controls at 6,24 and $72 \mathrm{~h}$ time points (Fig. 4). These data are in agreement with iTRAQ-MS data at those times (Table 3). Most irradiated cells died after $72 \mathrm{~h}$.

\section{Discussion}

The use of iTRAQ-MS and $M S^{\mathrm{E}}$ enabled the examination of protein expression changes in irradiated murine endothelial cell cultures over a time course of up to $72 \mathrm{~h}$. The aim of our study was to identify potential protein targets in AVM endothelium that discriminate these vessels from normal vessels; these proteins will be investigated for the molecular therapy of brain AVMs to promote rapid thrombosis after radiosurgery.

In general, the proteomics investigation of bEnd. 3 cell cultures revealed that numerous membrane proteins were differentially expressed between irradiated and nonirradiated cells. Many of those were up-regulated in the irradiated cells, especially $24 \mathrm{~h}$ post-irradiation. The most 


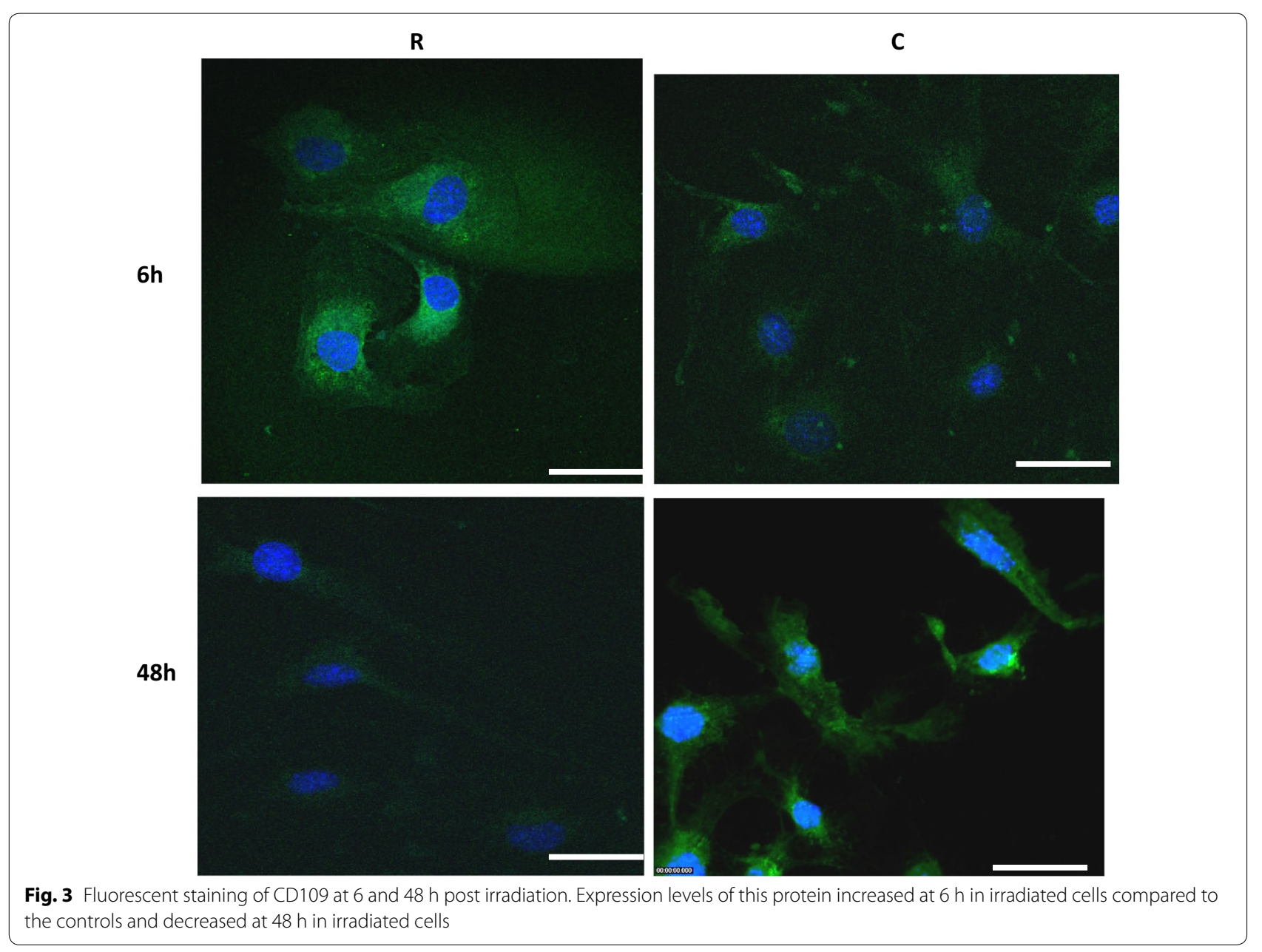

significant were PECAM-1, cadherin 5, PDI, integrin alpha 5, integrin alpha 6, integrin beta 1, CD109, EPCR and multimerin 2 . The up-regulation of four of these proteins was confirmed by immunocytochemistry.

\section{iTRAQ-MS data}

Eleven proteins were significantly differentially expressed in at least two out of the three iTRAQ-MS analyses at different time points, some were membrane proteins and some not, but mostly were up regulated in the irradiated cells (Table 1). Our primary focus was on the up-regulated membrane proteins in the irradiated cells at different time points and those were PECAM-1, Cadherin-5, PDI, CD109, integrin alpha-5 and integrin alpha-6 (Table 2).

PECAM-1 (or CD31) was up-regulated in irradiated cells at 24 and $72 \mathrm{~h}$ by 1.45 - and 1.17 -fold respectively. PECAM-1 is a vascular endothelial cell adhesion molecule that makes up the majority of endothelial cell intercellular junctions [41]. It is also expressed in platelets, macrophages and lymphocytes, and plays important roles in angiogenesis, regulation of integrin-mediated cell adhesion, and thrombosis [24].

PECAM-1 is a diagnostic membrane protein used to demonstrate the presence of endothelial cells in histological tissues [40, 42]. It is also expressed in certain tumours, which can imply a rapidly growing tumour because of its involvement in angiogenesis, for this reason PECAM-1 has been used as an angiogenic target in cancer therapies $[5,25]$. Previous in vitro studies in human and animal cell cultures showed that PECAM-1 expression increased when endothelial cells were exposed to irradiation doses from 10 to 20 Gy [11].

Cadhrein-5 (CD144) is another vascular endothelial cell adhesion molecule, belonging to the family of cadherins. Cadherin 5 is required for maintaining a restrictive endothelial barrier and is essential for proper vascular development [3]. Previous studies on cadherin 5 response to irradiation showed similar expression to that of PECAM-1 [1]. Our data are in agreement with those studies, as cadherin 5 expression was up-regulated in irradiated cells by 1.6 -fold at $24 \mathrm{~h}$ of irradiation. 


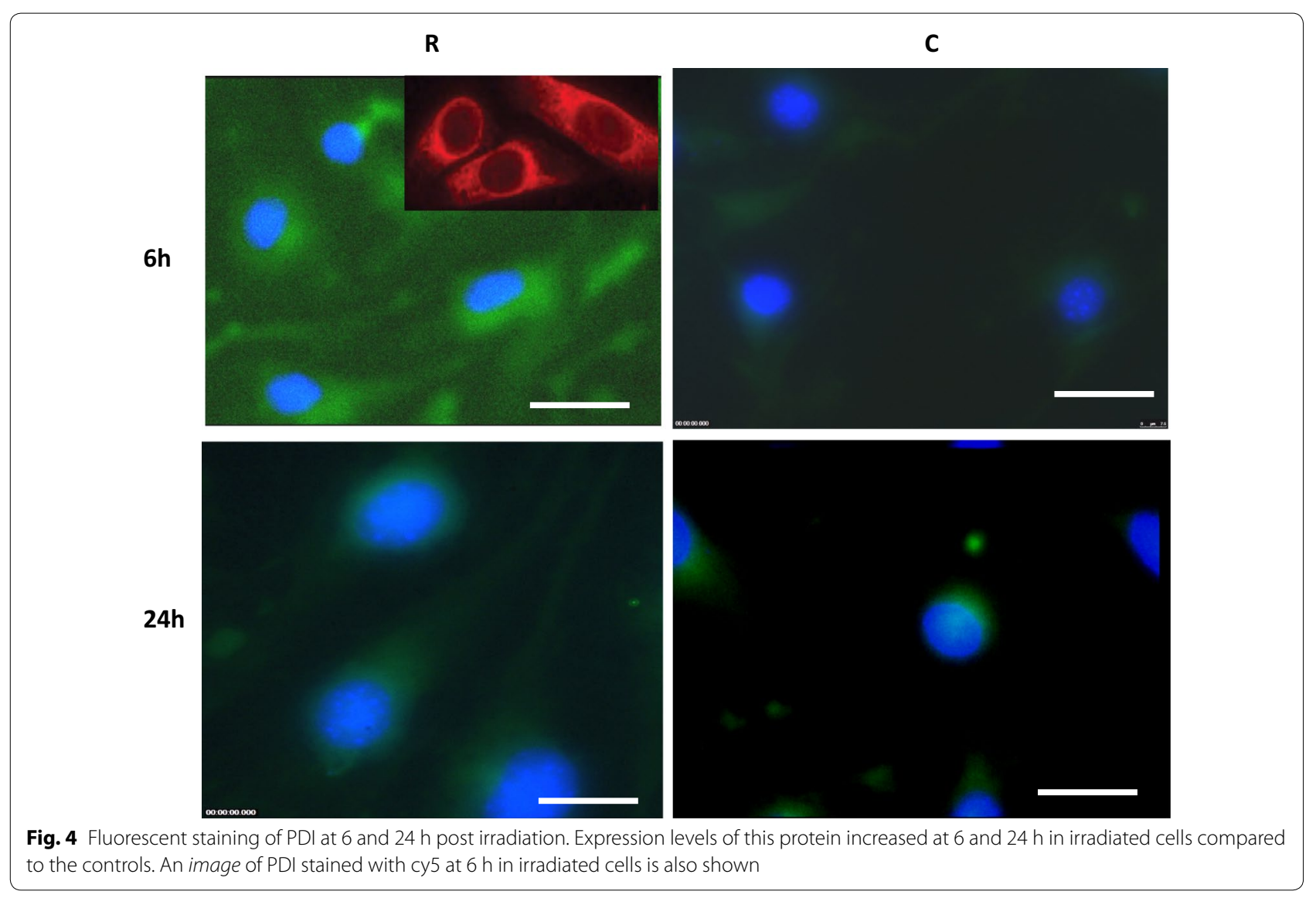

Table 1 Average protein expression ratios (control: irradiated), in at least two out of three iTRAQ experiments and the time point at which they showed significant up or down regulation or (fold change) with $p<0.05$

\begin{tabular}{|c|c|c|c|c|}
\hline Protein & $\begin{array}{l}\text { Ave }(R: C) \\
6 \mathrm{~h}\end{array}$ & $\begin{array}{l}\text { Ave (R:C) } \\
24 \mathrm{~h}\end{array}$ & $\begin{array}{l}\text { Ave (R:C) } \\
48 \mathrm{~h}\end{array}$ & $\begin{array}{l}\text { Ave (R:C) } \\
72 \mathrm{~h}\end{array}$ \\
\hline Cadherin- $5^{\mathrm{a}}$ & 1.00 & 1.00 & 0.80 & 1.00 \\
\hline CD109 & 1.00 & 1.00 & 0.66 & 1.00 \\
\hline $\begin{array}{l}\text { Protein disulfide } \\
\text { Isomerise (PDI) }\end{array}$ & 1.40 & 1.00 & 1.00 & 1.00 \\
\hline Actin cytoplasmic 2 & 1.00 & 1.00 & 0.81 & 1.00 \\
\hline Filamin B & 1.26 & 1.00 & 1.00 & 1.00 \\
\hline Lamin & 1.00 & 1.00 & 1.53 & 1.00 \\
\hline Plectin & 1.14 & 1.00 & 1.28 & 1.18 \\
\hline Vimentin & 1.36 & 1.00 & 2.50 & 1.17 \\
\hline Myosin & 1.00 & 1.25 & 1.00 & 1.28 \\
\hline Histon $\mathrm{H} 2 \mathrm{~A}$ & 1.00 & 1.00 & 3.10 & 1.00 \\
\hline Histon $\mathrm{H} 4$ & 1.00 & 1.00 & 1.00 & 0.42 \\
\hline
\end{tabular}

a Membrane proteins

Protein disulfide isomerase (PDI), showed up-regulation in irradiated cells at 6,24 and $72 \mathrm{~h}$ by $1.40-, 1.45$ and 1.20 -fold, respectively (Table 2). PDI is an enzyme that acts on the cell surface as a reductase to cleave the disulfide bonds of proteins attached to the cell, while inside the cell it rearranges the disulfide bonds of newly forming proteins [43]. PDI is also found on the surface of platelets where it plays a role in the activation of intergrins that involves rearrangement of disulfide bonds mediated by PDI; this activation of integrins to the ligand binding state is an important part of platelet adhesion and secretion [28]. No previous evidence is available on the effect of irradiation on PDI expression in endothelial cells.

Integrins belong to a large family of transmembrane cell adhesion receptors that mediate interactions between adhesion molecules on adjacent cells and on the extracellular matrix. They exist as heterodimers, alpha and beta subunits, and play different roles in biological processes such as cell migration, wound healing and apoptosis [28, 45]. Integrin alpha 5 is a fibronectin receptor, and integrin alpha 6 is a receptor for laminin which is a major protein in the basal lamina $[19,44]$. Alpha- 5 beta- 1 integrin mediates the adhesion pathway employed by platelets in the presence of PDI enzyme that facilitate the disulfide exchange on the cell-surface receptors $[6,12]$. In our iTRAQ-MS study, the expression levels of integrin 
Table 2 Up-regulated membrane proteins of bEnd.3 cells at various time points and their average (irradiated: control) ratios, $p<0.05$

\begin{tabular}{llll}
\hline Protein name & $\begin{array}{l}(\mathbf{R}: \mathbf{C}) \\
\mathbf{6 h}\end{array}$ & $\begin{array}{l}\mathbf{( R : C )} \\
\mathbf{2 4} \mathbf{h}\end{array}$ & $\begin{array}{l}\mathbf{( R : C )} \\
\mathbf{7 2} \mathbf{~ h}\end{array}$ \\
\hline Cadherin-5 & 1.00 & 1.60 & 1.00 \\
PECAM-1 & 1.00 & 1.45 & 1.17 \\
Protein disulfide isomerase (PDI) & $1.40^{\mathrm{a}}$ & 1.45 & 1.20 \\
CD109 & 1.28 & 1.00 & 1.00 \\
Integrin alpha-5 & 1.21 & 1.41 & 0.87 \\
Integrin alpha-6 & 1.00 & 1.37 & 1.00 \\
\hline
\end{tabular}

${ }^{a}$ Average of 2/3 iTRAQ-MS

alpha 5 increased in irradiated cells at 6 and 24 h by 1.21 and 1.41-fold respectively, while integrin 6 expressions increased in irradiated cells at $24 \mathrm{~h}$ by 1.37 -fold, making them interesting targets for further investigation for the AVM therapy post radiosurgery.

A number of non-membrane proteins interestingly showed significantly increased expression in the irradiated cells at different time points (Table 1), those were myosin, plectin, vimentin, lamin, actin cytoplasmic 2 and filamin B, which mainly connects cell membrane constituents to the cytoskeleton and maintain cell integrity [26], while histone $\mathrm{H} 2 \mathrm{~A}$ is involved in the structure of chromatin [46]. The expression patterns of these proteins are intriguing; they could potentially be targeted with the use of ligands to deliver thrombotic agents to AVM vessels. We have used Sulfo-NHS-LC-biotin in this study, which is known to inhibit cell membrane penetration [32]. Hence the presence of cytoplasmic and some nucleus proteins may be the result of radiation-stimulated surface expression. Previous in vitro studies of endothelial cells have shown cell surface translocation of intracellular proteins in response to irradiation [29, 34]. However the possibility of some biotin permeation cannot be excluded (Table 3).

\section{$\mathrm{MS}^{\mathrm{E}}$ data}

The most extensive membrane protein up-regulation in the irradiated cells was observed at the $24 \mathrm{~h}$ time point. Those membrane proteins were PECAM-1, cadherin 5,

Table 3 Membrane proteins of bEnd.3 identified in irradiated (R) and control (C) samples at 6, 24 and 48 h after irradiation, their average masses, average concentration on column (fmol) and number of replication in the MS runs; $n=6(R)$; $n=6(C)$

\begin{tabular}{|c|c|c|c|c|c|c|c|}
\hline Time point & Protein name & MW (Da) & $\begin{array}{l}\text { Ave (fmol) } \\
\text { in } R\end{array}$ & $\begin{array}{l}\text { Protein } \\
\text { replication }\end{array}$ & $\begin{array}{l}\text { Ave (fmol) } \\
\text { in C }\end{array}$ & $\begin{array}{l}\text { Protein } \\
\text { replication }\end{array}$ & $\begin{array}{l}\text { Fold change } \\
(\mathrm{R}: \mathrm{C})\end{array}$ \\
\hline \multirow[t]{7}{*}{$6 \mathrm{~h}$} & PECAM-1 & $82,118.1$ & 21.7 & 1 & 13.5 & 1 & 1.6 \\
\hline & Cadherin 5 & $88,188.2$ & 0.01 & 1 & 6.5 & 1 & 0 \\
\hline & Annexin A2 & $38,961.4$ & 6.4 & 1 & 6.7 & 1 & 1 \\
\hline & Multimerin 2 & $105,833.7$ & 0.01 & 1 & 6.5 & 1 & 0 \\
\hline & Integrin beta 1 & 91,482 & 0.01 & 1 & 6.4 & 1 & 0 \\
\hline & Ras related Rab-1B & $22,358.3$ & 2.4 & 1 & 0.01 & 1 & 0 \\
\hline & Protein lunapark & $47,785.1$ & 13.2 & 1 & 0.01 & 1 & 0 \\
\hline \multirow[t]{9}{*}{$24 \mathrm{~h}$} & PECAM-1 & $82,118.1$ & 67.9 & 5 & 52 & 5 & 1.2 \\
\hline & Cadherin 5 & $88,188.2$ & 49 & 6 & 16.4 & 6 & 3 \\
\hline & Multimerin 2 & $105,833.7$ & 25.4 & 3 & 28.9 & 3 & 0.8 \\
\hline & Protein lunapark & $47,785.1$ & 23.2 & 1 & 0.01 & 1 & 0 \\
\hline & Endothelial protein C receptor & $27,668.3$ & 7.2 & 1 & 0.01 & 1 & 0 \\
\hline & Surface glycoprotein & 72,515 & 0.01 & 1 & 13.4 & 1 & 0 \\
\hline & Annexin A2 & $38,961.4$ & 9 & 1 & 9.4 & 1 & 1 \\
\hline & Integrin beta 1 & 91,482 & 31.7 & 3 & 0.01 & 1 & 0 \\
\hline & Fibroblast growth factor 8 & $23,891.9$ & 19.8 & 1 & 0.01 & 1 & 0 \\
\hline \multirow[t]{8}{*}{$48 \mathrm{~h}$} & PECAM-1 & $82,118.1$ & 55.4 & 5 & 36.7 & 3 & 1.5 \\
\hline & Annexin A2 & $38,961.4$ & 0.01 & 1 & 10.4 & 1 & 0 \\
\hline & Cadherin 5 & $88,188.2$ & 31.1 & 3 & 18.3 & 1 & 1.7 \\
\hline & Multimerin 2 & $105,833.7$ & 19.8 & 3 & 21.7 & 3 & 0.9 \\
\hline & Cell surface glycoprotein & 72,515 & 15.8 & 1 & 0.01 & 1 & 0 \\
\hline & Integrin beta 1 & 91,482 & 15.1 & 1 & 0.01 & 1 & 0 \\
\hline & Ras related Rab 35 & $23,310.4$ & 10.7 & 1 & 0.01 & 1 & 0 \\
\hline & Fibroblast growth factor 8 & $30,647.8$ & 0.01 & 1 & 4.9 & 1 & 0 \\
\hline
\end{tabular}


integrin beta 1, endothelial protein $C$ receptor (EPCR), and multimerin 2 . At the $24 \mathrm{~h}$ time point, these proteins were significantly up-regulated by 3.8-, 5.7-, 14.2-, 17.7and 3.2-fold respectively (Table 4). At the $48 \mathrm{~h}$ time point, PECAM-1 showed significant up-regulation in irradiated cells, by 2.3 -fold, while cadherin 5 and multimerin 2 were up-regulated by 3.3 - and 1.0-fold, respectively (Table 5). These results are in accordance with the iTRAQ-MS data and with the immunocytochemistry data.

Since PECAM-1 was up-regulated significantly in both iTRAQ-MS and $M S^{E}$ data at various time points in irradiated cells, future studies will investigate PECAM-1 protein as a target for AVM molecular therapy with the use of ligands that have been suggested for PECAM-1, such as $\alpha_{\mathrm{v}} \beta_{3}$ integrin, CD38, CD51 and CD61 [17, 42].

Cadherin 5 expression was also significantly up-regulated in both iTRAQ-MS and $\mathrm{MS}^{\mathrm{E}}$ in irradiated cells at various time points. Therefore future work will further investigate the role of cadherin 5 in thrombosis of AVM vessels post irradiation.

Integrin beta- 1 is another protein that was up-regulated significantly in irradiated cells at $24 \mathrm{~h}$ by 14.2 -fold, post irradiation with $\mathrm{MS}^{\mathrm{E}}$ analysis (Table 4). Integrin beta- 1 (or CD29) is a membrane receptor belonging to the family of integrins, and is involved in cell adhesion and recognition in a variety of biological processes including embryogenesis, haemostasis, and metastatic diffusion of tumour cells [30]. The subfamily alpha 2-beta $1\left(a_{2} \beta_{1}\right)$ integrin serves as a receptor for collagens, laminin, and many other ligands, and it has been extensively studied as a collagen receptor on platelets [33]. Many studies suggested that $\mathrm{a}_{2} \beta_{1}$ is a crucial mediator of platelet adhesion to collagen in the vessel wall after vascular injury, and that this interaction is required for proper haemostasis and thrombosis [33]. In 2002 a study by Cordes et al. [4] showed that integrin beta-1 was up-regulated post irradiation in human lung tumor cells in vitro. The role of integrin beta-1 receptor in thrombosis makes it a potential protein target for investigation for the AVM molecular therapy post radiosurgery.

Endothelial protein $C$ receptor (EPCR) or (CD201) is an additional membrane protein that was up-regulated significantly in the irradiated cell cultures at 24 time point by 17.7 -fold (Table 4 ). This protein is a receptor for activated protein $C$ (APC), which is a serine protease involved in the blood coagulation pathway [10]. Protein $\mathrm{C}$, also known as autoprothrombin IIA and blood coagulation factor XIV, which is an inactive protein, the active form plays important role in regulating thrombosis [13]. Protein $\mathrm{C}$ is activated by binding to thrombin, and protein C's activation is stimulated by the presence of thrombomodulin and EPCR, therefore activated protein $\mathrm{C}$ is mainly found in endothelial cells of blood vessels walls $[10,31]$. Due to EPCRs role in regulating thrombosis it makes this protein a worthy candidate for investigation in AVM molecular therapy, perhaps adding APC resistance factors after radiosurgery may induce thrombosis readily in AVM vessels.

Table 4 Membrane protein upregulation in irradiated (R) versus control (C) cells at 24 h post irradiation, their accession number, molecular weight, average concentration on column ( $\mathrm{fmol}$ ) and average concentration ratios (irradiated: control); $n=6(R) ; n=6(C)$

\begin{tabular}{|c|c|c|c|c|c|c|c|c|}
\hline Protein name & Accession\# & MW & Ave fmol in $R$ & SD & Ave fmol in C & SD & Ave $(R: C)$ & $p$ \\
\hline PECAM-1 & Q08481 & $82,118.14$ & 88.4 & 57 & 23.4 & 26.1 & 3.8 & 0.019 \\
\hline Cadherin 5 & P55284 & $88,188.25$ & 58.7 & 33 & 10.3 & 10.2 & 5.7 & 0.010 \\
\hline Integrin beta 1 & P09055 & $91,481.98$ & 26.9 & 16 & 1.9 & 0.2 & 14.2 & 0.004 \\
\hline EPCR & Q64695 & $27,668.34$ & 35.3 & 18 & 2 & 0.2 & 17.7 & 0.058 \\
\hline Multimerin 2 & A6H6E2 & $105,833.7$ & 39.3 & 22 & 12.4 & 12.1 & 3.2 & 0.033 \\
\hline
\end{tabular}

Table 5 Membrane protein upregulations in irradiated (R) versus control (C) cells at $48 \mathrm{~h}$ post irradiation, their accession number, molecular weight, average concentration on column ( $\mathrm{fmol}$ ) and average concentration ratios (irradiated: control); $n=6(R) ; n=6(C)$

\begin{tabular}{llllrrrrr}
\hline Protein name & Accession\# & MW & $\begin{array}{l}\text { Ave } \\
\text { fmol in R }\end{array}$ & SD & Ave fmol in C & SD & Ave (R:C) & $\boldsymbol{p}$ \\
\hline PECAM-1 & Q08481 & $82,118.14$ & 45.0 & 23.0 & 19.2 & 17.9 & 2.3 & 0.056 \\
Cadherin 5 & P55284 & $88,188.25$ & 16.8 & 15.7 & 5.1 & 6.5 & 3.3 & 0.136 \\
Multimerin 2 & A6H6E2 & $105,833.7$ & 11.4 & 9.5 & 11.8 & 11.1 & 1.0 & 0.938 \\
\hline
\end{tabular}


Multimerin 2 was up-regulated in irradiated cell at $24 \mathrm{~h}$ by 3.2-fold (Table 4). Multimerin 2 is a basement membrane glycoprotein secreted into the extracellular matrix that inhibits endothelial cells motility and negatively regulates angiogenesis $[2,20]$. Some in vitro and in vivo studies suggested that multimerin 2 may reduce tumour angiogenesis and growth by interfering with the vascular endothelial growth factor (VEGF-A/VEGFR2) pathway thus making it a potential candidate in developing cancer treatment $[16,20]$. While multimerin 1 in platelets plays a role in thrombosis [15], mulimerin 2 doesn't, and there is no previous evidence of multimerin 2 response to irradiation.

In conclusion, cell surface protein biotinylation and iTAQ-MS and $M S^{\mathrm{E}}$ proteomics analysis successfully identified membrane proteins from murine brain endothelial cell cultures in response to irradiation. The up-regulated membrane proteins identified from this novel research are currently being investigated as potential targets for the ligand-directed molecular targeting trials in the rat model on AVM, along with the membrane proteins identified from the proteomics analysis of the rat model of AVM in response to irradiation [37], manuscript in preparation for submission).

Future study will further include irradiation-induced changes in human primary endothelial cell cultures from resected AVM tissues, using proteomic analysis. Candidate proteins then will be investigated for use in liganddirected human vascular targeting trials to promote rapid thrombosis in AVM vessels after radiosurgery. This is especially important for patients who currently have to wait up to 3 years after undergoing radiosurgery, for their AVM to be occluded completely, while they remain at risk of haemorrhage.

\section{Additional files}

Additional file 1: Table S1. Membrane proteins in all 3 iTRAQs

experiments.

Additional file 2: Table S2. One of iTRAQ-MS raw data file.

Additional file 3: Table S3. All proteins identified in 2 MSES.

Additional file 4: Table S4. MSE raw data for control at $6 \mathrm{~h}$, one fraction.

Additional file 5: Table S5. Combining Tables 1, 2, 3, 4, 5 and the stain-

ing data, all in one table.

\section{Authors' contributions}

MS: prepared and performed all the experiments descried in this manuscript, analysed all the data, and wrote the manuscript. RROL: helped with the biotinylation optimization protocol on the cell cultures for $\mathrm{MS}^{\mathrm{E}}$ analysis. NR: run the prepared samples on the mass spec instrument. JAL: supervised the MS ${ }^{\mathrm{E}}$ proteomics experiments. MPM: supervised the iTRAQ-MS proteomics experiments, edited the manuscript. MAS: the PI of this project, edited the manuscript. All authors read and approved the final manuscript.

\begin{abstract}
Author details
${ }^{1}$ Department of Clinical Medicine, Faculty of Medicine and Health Sciences, Macquarie University, North Ryde, NSW 2109, Australia. ${ }^{2}$ David Geffen School of Medicine, Department of Biological Chemistry, University of California Los Angeles (UCLA), 611 Charles E. Young Drive East, Los Angeles, CA 90095, USA. ${ }^{3}$ Australian Proteome Analysis Facility (APAF), Department of Chemistry and Bimolecular Sciences, Macquarie University, North Ryde, NSW 2109, Australia.
\end{abstract}

\section{Acknowledgements}

MAS and MPM acknowledge funding from the National Health and Medical Research Council of Australia. Aspects of this research were conducted at the Australian Proteome Analysis Facility (APAF) supported by the Australian Government's National Collaborative Research Infrastructure Scheme (NCRIS). The MS ${ }^{\mathrm{E}}$ analysis was undertaken at Prof. Joseph Loo laboratory at UCLA. We acknowledge the support of the Radiation Oncology Department at Macquarie University Hospital, especially Michael Grace. We are grateful to UCLA Department of Radiation Oncology for allowing access to their facilities.

\section{Competing interests}

The authors declare that they have no competing interests.

\section{Availability of data and materials}

All data generated or analysed during this study are included in this manuscript. The supplementary files and couple of the raw data files were uploaded along with the manuscript.

\section{Funding}

We acknowledge the funding from the National Health and Medical Research Council of Australia. Aspects of this research were conducted at the Australian Proteome Analysis Facility (APAF) supported by the Australian Government's National Collaborative Research Infrastructure Scheme (NCRIS).

\section{Publisher's Note}

Springer Nature remains neutral with regard to jurisdictional claims in published maps and institutional affiliations.

Received: 19 December 2016 Accepted: 26 April 2017

Published online: 16 May 2017

\section{References}

1. Akimoto T, Mitsuhashi N, Saito Y, Ebara T, Niibe H. Effect of radiation on the expression of $\mathrm{E}$-cadherin and a-catenin and invasive capacity in human lung cancer cell line in vitro. Int J Radiat Oncol Biol Phys. 1998;41(5):1171-6.

2. Christian S, Ahorn H, Novatchkova M, Garin-Chesa P, Park JE, Weber G, Eisenhaber F, Rettig WJ, Lenter MC. Molecular cloning and characterization of EndoGlyx-1, an EMILIN-like multisubunit glycoprotein of vascular endothelium. J Biol Chem. 2001;276:48588-95.

3. Corada M, Zanetta L, Orsenigo F, Breviario F, Lampugnani MG, Bernasconi S, Liao F, Hicklin DJ, Bohlen P, Dejana E. A monoclonal antibody to vascular endothelial-cadherin inhibits tumor angiogenesis without side effects on endothelial permeability. Blood. 2001;100(3):905-11.

4. Cordes N, Blaese MA, Meineke V, Van Beuningen D. lonizing radiation induces up-regulation of functional beta 1-integrin in human lung tumour cell lines in vitro. Int J Radiat Biol. 2002;78(5):347-57.

5. DeLisser HM, Christofidou-Solomidou M, Strieter RM, Burdick MD, Robinson CS, Wexler RS, Kerr JS, Garlanda C, Merwin JR, Madri JA, Albelda SM. Involvement of endothelial PECAM-1/CD31 in angiogenesis. Am J Pathol. 1997;151(3):671-7.

6. Essex W, Chen K, Swiatkowska M. Localization of protein disulfide isomerase to the external surface of the platelet plasma membrane. Blood. 1995;86:2168-73.

7. Ferch RD, Morgan MK. High-grade arteriovenous malformations and their management. J. Clin Neurosci. 2002;9(1):37-40. 
8. Friedlander RM. Arteriovenous malformations of the brain. N Engl J Med. 2007;356:2704-12.

9. Friedman WA, Bova FJ, Bollampally S, Bradshaw P. Analysis of factors predictive of success or complications in arteriovenous malformation radiosurgery. Neurosurgery. 2003;52(2):296-307.

10. Fukudome K, Esmon C. Identification, cloning, and regulation of a novel endothelial cell protein C/activated protein C receptor. J Biol Chem. 1994;269(42):26486-91.

11. Gaugler MH, Vereycken-Holler V, Squiban C, Aigueperse J. PECAM-1 (CD31) is required for interactions of platelets with endothelial cells after irradiation. Thromb Haemost. 2004:2(11):2020-6.

12. Giancotti FG, Ruoslahti E. Integrin signaling. Science. 1999;285(5430):1028-32.

13. Hall J, Morton I. Concise dictionary of pharmacological agents: properties and synonyms, vol 255, no. 12. London: Kluwer Academic; 1999. p. $5521-4$

14. Han PP, Ponce FA, Spetzler RF. Intention-to-treat analysis of Spetzler-Martin grades IV and $V$ arteriovenous malformations: natural history and treatment paradigm. J Neurosurg. 2003;98(1):3-7.

15. Hayward CP, Warkentin TE, Horsewood P, Kelton JG. Multimerin: a series of large disulfide-linked multimeric proteins within platelets. Blood. 1991;77(12):2556-60.

16. Huang SW, Lien JC, Kuo SC, Huang TF. Antiangiogenic mechanisms of PJ-8, a novel inhibitor of vascular endothelial growth factor receptor signaling. Carcinogenesis. 2012;33(5):1022-30.

17. Huss WJ, et al. Angiogenesis and prostate cancer: identification of a molecular progression switch. Cancer Res. 2001;61:2736-43.

18. Jeffree R, Stodley MA. Postnatal development of arteriovenous malformations. Pediatr Neurosurg. 2009;45:296-304.

19. Lee EC, Lotz MM, Steele GD Jr, Mercurio AM. The integrin alpha 6 beta 4 is a laminin receptor. J Cell Biol. 1992;117(3):671-8.

20. Lorenzon E, Colladel R, Andreuzzi E, Marastoni S, Todaro F, Schiappacassi M, Ligresti G, Colombatti A, Mongiat M. MULTIMERIN2 impairs tumor angiogenesis and growth by interfering with VEGF-ANEGFR2 pathway. Oncogene. 2012;31(26):3136-47.

21. Lunsford LD, Niranjan A, Kondziolka D, Sirin S, Flickinger JC. Arteriovenous malformation radiosurgery: a twenty year perspective. Clin Neurosurg. 2008;55:108-19.

22. Maruyama K, Kawahara N, Shin M. The risk of haemorrhage after radiosurgery for cerebral arteriovenous malformations. N Engl J Med. 2005;352:146-53.

23. McCormick WF. The pathology of vascular ("arteriovenous") malformations. J Neurosurg. 1966;24:807-16.

24. Newman J, Berndt C, Gorski C, White I, Lyman S, Paddock C, Muller A. PECAM-1 (CD31) cloning and relation to adhesion molecules of the immunoglobulin gene superfamily. Science. 1990;247:1219-22.

25. Ouyang JS, Li YP, Chen CS, Chen JJ, Chen TK, Cai C, Yang L. Inhibition of lung tumour growth in nude mice by siRNACD31 targeting PECAM-1. Oncol Lett. 2014;8:33-40.

26. Pfendner E, Rouan F, Uitto J. Progress in epidermolysis bullosa: the phenotypic spectrum of plectin mutations. Exp Dermatol. 2005;14(4):241-9.

27. Phillips M, Stelzer KJ, Griffen TW. Stereotactic radiosurgery: a review and comparison of methods. J Clin Oncol. 1994:12:1985-99.

28. Popielarski M, Ponamarczuk H, Sobierajska K, Swiątkowska M. Role of protein disulfide isomerase in activation of integrins. Postepy Hig Med Dosw. 2014;68:66-83.

29. Prunotto M, Carnevali ML, Candiano G, Murtas C, Bruschi M, Corradini E, et al. Autoimmunity in membranous nephropathy targets aldose reductase and SOD2. J Am Soc Nephrol. 2010;21(507-19):22.

30. Radford KJ, Thorne RF, Hersey P. CD63 associates with transmembrane 4 superfamily members, CD9 and CD81, and with beta 1 integrins in human melanoma. Biochem Biophys Res Commun. 1996;222(1):13-8.

31. Rothbarth K, Dabaghian AR, Stammer H, Werner D. One single mRNA encodes the centrosomal protein CCD41 and the endothelial cell protein C receptor (EPCR). FEBS Lett. 1999;458(1):77-80.
32. Rybak JN, Ettorre A, Kaissling B, Giavazzi R, Neri D, Elia G. In vivo protein biotinylation for identification of organ-specific antigens accessible from the vasculature. Nat Methods. 2005;2:291-8.

33. Santoro A, Tursz T, Mouridsen H, Verweij J, Steward W, Somers R, Buesa J, Casali P, Spooner D, Rankin E, et al. Doxorubicin versus CYVADIC versus doxorubicin plus ifosfamide in first-line treatment of advanced soft tissue sarcomas: a randomized study of the European Organization for Research and Treatment of Cancer Soft Tissue and Bone Sarcoma Group. J Clin Oncol. 1995;13(7):1537-45.

34. Sasaki M, Miyakoshi M, Sato Y, Nakanuma Y. Increased expression of mitochondria proteins associated with autophagy in biliary epithelial lesions in primary biliary cirrhosis. Liver Int. 2013;33:312-20.

35. Simonian M, Molloy MP, Stoodley MA. In vitro and in vivo biotinylation of endothelial cell surface proteins in the pursuit of targets for vascular therapies for brain AVMs. Metabol J. 2012;1:1-4.

36. Simonian M, Ogorzalek Loo RR, Loo JA, Stoodley MA, Molloy MP. Proteomics detection of endothelial cell surface proteins following irradiation as potential targets for brain arteriovenous malformations molecular therapies. Proteomics Bioinform J. 2014;1 (1):1-6.

37. Simonian M, Shirasaki D, Lee V, Ogorzalek Loo RR, Loo JA, Molloy MP, Stoodley MA. Proteomics identification of radiation-induced changes of membrane proteins in the rat model of arteriovenous malformation in pursuit of targets for brain AVM molecular therapy. 2015 (manuscript in preparation for submission)

38. Spetzler RF, Martin NA. A proposed grading system for arteriovenous malformations. J Neurosurg. 1986;65:476-83.

39. Spetzler RF, Hargraves RW, McCormick PW, Zabramski JM, Flom RA. Relationship of perfusion pressure and size to risk of hemorrhage from arteriovenous malformations. J Neurosurg. 1992;76:918-23.

40. Vanzulli S, et al. Detection of endothelial cells by MEC 13.3 monoclonal antibody in mice mammary tumors. Biocell. 1997;21:39-46.

41. Varon D, Jackson DE, Shenkman B, Dardik R, Tamarin I, Savion N, Newman PJ. Platelet/endothelial cell adhesion molecule-1 serves as a costimulatory agonist receptor that modulates integrin-dependent adhesion and aggregation of human platelets. Blood. 1998;91(2):500-7.

42. Vecchi A, et al. Monoclonal antibodies specific for endothelial cells of mouse blood vessels. Their application in the identification of adult and embryonic endothelium. Eur J Cell Biol. 1994;63:247-54.

43. Wilkinson B, Gilbert H. Protein disulfide isomerase. Biopysica Acta. 2004:1:35-44.

44. Wu C, Bauer JS, Juliano RL, McDonald JA. The alpha 5 beta 1 integrin fibronectin receptor, but not the alpha 5 cytoplasmic domain, functions in an early and essential step in fibronectin matrix assembly. J Biol Chem. 1993:268(29):21883-8.

45. Xiong JP, Stehle T, Diefenbach B. Crystal structure of the extracellular segment of integrin alpha V beta 3. Science. 2001:294(5541):339-45.

46. Youngson RM. Collins dictionary of human biology. Glasgow: HarperCollins; 2006. ISBN 0-00-722134-7.

\section{Submit your next manuscript to BioMed Central and we will help you at every step:}

- We accept pre-submission inquiries

- Our selector tool helps you to find the most relevant journal

- We provide round the clock customer support

- Convenient online submission

- Thorough peer review

- Inclusion in PubMed and all major indexing services

- Maximum visibility for your research

Submit your manuscript at www.biomedcentral com/submit
BioMed Central 